Article

\title{
Food Waste Reduction: A Test of Three Consumer Awareness Interventions
}

\author{
Tammara Soma ${ }^{1, *(D)}$, Belinda $\mathrm{Li}^{2}$ and Virginia Maclaren ${ }^{3}$ \\ 1 School of Resource and Environmental Management, Simon Fraser University, \\ Burnaby, BC M5S 3G3, Canada \\ 2 Food Systems Lab, Simon Fraser University, Burnaby, BC V5A 1S6, Canada; belinda_li@sfu.ca \\ 3 Department of Geography \& Planning, University of Toronto, Toronto, ON M5S 3G3, Canada; \\ maclaren@geog.utoronto.ca \\ * Correspondence: tammara_soma@sfu.ca
}

Received: 13 December 2019; Accepted: 22 January 2020; Published: 26 January 2020

\begin{abstract}
Halving food waste by 2050 as per the Sustainable Development Goal 12.3 is key to securing a food system that is sustainable. One approach to reducing household food waste is through education campaigns. We recruited 501 households divided into three types of intervention groups and compared with a control group to better understand the efficacy of diverse education campaign approaches. Food waste interventions included a passive approach (handouts), a community engagement approach, and a gamification approach. We conducted waste audits, household surveys (pre- and post-intervention), and a focus group at the end of the campaign. The passive and gamification groups had similarly high levels of participation, while participation in the community group was very low. The passive group and the gamification group had higher self-reported awareness of food wasting after the campaign and lower food wastage than the control group. Waste audits found marginally significant differences between the game group and the control $(p=0.07)$ and no difference between the other campaign groups and the control group in edible food wasted. Frequent gamers were found to generate less edible food waste than infrequent gamers. We conclude that the evidence about the potential for gamification as an effective education change tool is promising and we recommend further study.
\end{abstract}

Keywords: food waste; awareness campaigns; gamification; intervention; consumer behaviour

\section{Introduction}

The wasting of food produced for human consumption has been connected to issues such as climate change, biodiversity loss, water loss, soil degradation, and hunger [1]. More recently, the issue of food waste has been linked to nutrition losses in diets [2,3], and these losses have important implications for the sustainability of diets and planetary health [4]. Efforts to prevent and reduce consumer food waste have included reducing cafeteria plate waste at an institutional level [5], changing guidelines around nutrition [6], food sharing apps [7], tailored home-based interventions [8], public commitments and goal setting [9], and information campaigns to increase food literacy. This last tool is the focus of our current study.

In the past decade, awareness campaigns have increasingly made it into mainstream media and have become one of the most widely used interventions for food waste education [10]. In 2007, the United Kingdom (UK) embarked on a major food waste campaign entitled "Love Food Hate Waste" led by WRAP (The Waste and Resource Action Programme). The Love Food Hate Waste model has been franchised globally, including in Canada, with the campaign promoting recipes to transform leftovers, sharing catchy marketing campaigns, and offering tips and strategies to prevent food waste. 
In the United States, consumer education (awareness) campaigns were one of the highest ranked solutions for food waste reduction according to a report by ReFED [11] with an estimated food waste diversion potential of 584,000 tons/year and an economic value (aggregated financial benefit to society minus investments and costs) of $\$ 2.65$ billion USD/year. Large-scale national awareness campaigns in the U.S. include the Natural Resources Defense Council's "Save the Food" campaign [12], as well as the United States Environmental Protection Agency's (US EPA) "Food: Too Good to Waste" [11]. Such campaigns often feature a website with practical advice for consumers to reduce food waste at home and are disseminated via outlets such as television, radio, web advertisements, and social media. Local authorities (e.g., municipalities), not-for-profit organizations, and industry may serve as partners to implement campaigns in the community, such as by hosting public events and workshops. Some campaigns, such as ReFed's "Food: Too Good to Waste", focus almost exclusively on small-scale implementation using community-based social marketing (CBSM) strategies [13]. In Canada, notable awareness campaigns include "Love Food Hate Waste" in Metro Vancouver and the City of Toronto [14] and Sauve Ta Bouffe in Québec [15]. The National Zero Waste Council (NZWC), an NGO based in Metro Vancouver with a mission to promote waste prevention and a circular economy, has taken a leadership role in launching the awareness initiatives across Canada. The Council's National Food Waste Reduction Strategy identifies the development of a national food waste reduction campaign as a key priority [14].

Awareness campaigns are antecedent interventions that aim to influence one or more behavioural determinants prior to the performance of an environmental behaviour [16]. Information is meant to increase knowledge about the consequences of unsustainable behaviour and how to change that behaviour. For example, Parizeau et al. [17] found that households with higher awareness of food waste as a social problem produced fewer types of food waste. Awareness campaigns have been identified by some as a crucial instrument for influencing food wasting behaviour [10]. Others have found that information interventions alone have had mixed results, with little to no effect on pro-environmental behaviour [16,18] and limited effects on food waste behaviour [19,20].

Many theoretical explanations of how information influences pro-environmental behaviour have relied on the Theory of Reasoned Action (TRA) and the Theory of Planned Behaviour (TPB), although their adequacy has been questioned because of the models' assumption that intention leads to behaviour [21] and their omission of factors such as routines, socio-demographics, and context [22]. Expanded TRA and TPB models have added knowledge about pro-environmental behaviour as an explanatory variable. In a study of waste minimization behaviour based on the TRA model, Barr [23] found that information was one of a number of variables that directly influenced packaging and reusable product choices. In contrast, Visschers et al. [24] found no relationship in their TPB model between knowledge of practical skills for reducing food waste and the amount of food wasted. They speculated that knowledge instead influenced food waste behaviour indirectly through perceived behavioural control.

While we acknowledge that the role of information in changing food waste behaviour may be limited and may not influence behaviour directly but rather indirectly, our goal is to test a new form of knowledge and skill information delivery, namely gamification. We compare its effectiveness to community workshops and to a more traditional form of information delivery that relies on newsletters and prompts. This study therefore seeks to add to the food waste study literature that evaluates and assesses the efficacy of different types of information interventions for reducing food waste at the household level.

Very few studies on the effectiveness of food waste interventions at the household level have been undertaken [19]. Even fewer have examined the effectiveness of information interventions. Young et al. [25] found that social media campaigns reduced self-reported household food waste but not significantly more than that experienced by a control group. Shaw et al. [26] tested the impact of information leaflets that emphasized the financial and environmental benefits of reducing food waste, but a waste audit found no statistically significant difference in avoidable food waste compared to 
a control group before and after the intervention. Van der Werf et al. [27] tested a two-week information campaign consisting of messaging tailored to participants' economic self-interests. Households received information about reducing food waste in multiple ways, namely by means of a fridge magnet, freezer stickers, a postcard, a grocery list pad, a container designed to retain food freshness, and links to a website with food waste reduction tips. Using waste audits rather than self-reporting, they found that the campaign resulted in a 31\% reduction in food waste. In sum, the results of interventions aiming to increase awareness of food waste and the means of reducing food waste have been mixed to date.

It is notable that the measurement of food waste in some cases has relied on self-reporting/perception rather than an actual waste audit quantifying the reduction. Several studies have noted the limitations of using self-reporting to measure food waste [28], which, in some cases, can lead individuals to significantly underestimate reported amounts by $40 \%$ [29].

Another potential avenue for communicating food waste reduction practices and impacts is through community engagement. Yamakawa et al. [30] report that community engagement workshops were successful in reducing avoidable food waste for participants by as much as $50 \%$. The workshops were offered as part of WRAP UK Love Food Hate Waste campaign and provided information on food shopping, meal planning, best-before dates, recipes for leftovers, and opportunities for group activities.

A third approach is technology-based and can include the use of smart bins [31,32], bin-cams [33], and fridge-cams [34] to monitor and provide feedback on food waste. Gamification, which is usually delivered through technology such as apps, falls into this class of approaches. Gamification is the use of game elements and design in non-game contexts to promote behavioural change [35], the tracking of individual behaviours, and the provision of visual feedback on progress in the game [36]. The gamification intervention in our study consisted of a simple online educational trivia-based game with facts and strategies to help participants learn to reduce food waste. The game did not monitor or track participants' food waste. A review of studies on gamification found that points, leaderboards, and badges were the most common types of strategies used to boost motivation [37]. In a similar literature review of gamification studies focused on health and wellbeing, Johnson et al. [36] found that $59 \%$ of gamified interventions showed positive effects and $41 \%$ showed neutral or mixed effects. There were no interventions that showed only negative effects. Johnson et al.'s [38] review of gamification for reducing household energy consumption found positive effects on behaviour and knowledge outcomes. Gamification has not yet been tested in the context of household food waste reduction, to our knowledge.

We propose to examine the effectiveness of the three types of interventions described above in raising awareness of food waste as a problem and changing food waste behaviour. We measure the effectiveness of each intervention by using a pre-post design that asks about changes in self-reported food waste awareness before and after the interventions and relative to a control group. We measure changes in the amount of household food waste by means of household food waste audits before and after the interventions and by self-reported food waste behaviour changes in the survey after the interventions, relative to a control group. Our hypotheses are:

Hypothesis 1 (H1). Information campaigns using "passive" methods such as postcards, brochures, and prompts will increase awareness about food waste and reduce the amount of household food waste generated.

Hypothesis 2 (H2). Campaigns with community engagement activities in combination with an information campaign will increase awareness about food waste and reduce generation of household food waste more than a passive information campaign alone.

Hypothesis 3 (H3). Gamification approach in combination with a passive information campaign would increase awareness of food waste and reduce generation of household food waste more than the passive approach alone.

For all three hypotheses, we are interested in measuring not only whether participation in a campaign influences reported food wasting behaviour, awareness, and audited food waste amounts, 
but also whether respondents choose to participate in the campaign at all, i.e., by using the information resources provided, by participating in the community workshop, or by participating in the game.

\section{Materials and Methods}

\subsection{Research Design}

This study tested the three interventions over a twelve-week period. The core themes and content of the campaign topic were gleaned from several popular food waste campaigns including Love Food Hate Waste and Food: Too Good to Waste. The first method was an information-based campaign (the Information group) using more passive approaches. Participants received a booklet with information on why food waste is a problem, tips to reduce food waste at home, and a visible prompt in the form of a fridge magnet with storage tips (see Figure 1). Information interventions that include prompts have been shown to be more effective than information alone. They also received newsletters via email (or by mail for those without internet access) four times throughout the course of the campaign with tips for food storage, meal planning, shopping, understanding best-before dates, and recipes for using leftovers or slightly spoiled food. The second delivery method was an information-based campaign augmented by community workshops (the Community group). In addition to the information materials received by the Information group, participants received an invitation to attend a series of four community workshops that had a similar focus to the WRAP workshops described earlier, with presentations on food waste reduction, group discussions, group activities, watching videos together, and quizzes with small prizes. The first workshop focused on meal planning and using up leftovers, the second focused on proper food storage, the third on best-before dates, and the final workshop was a review and wrap-up on the importance of preventing and reducing food waste in general.

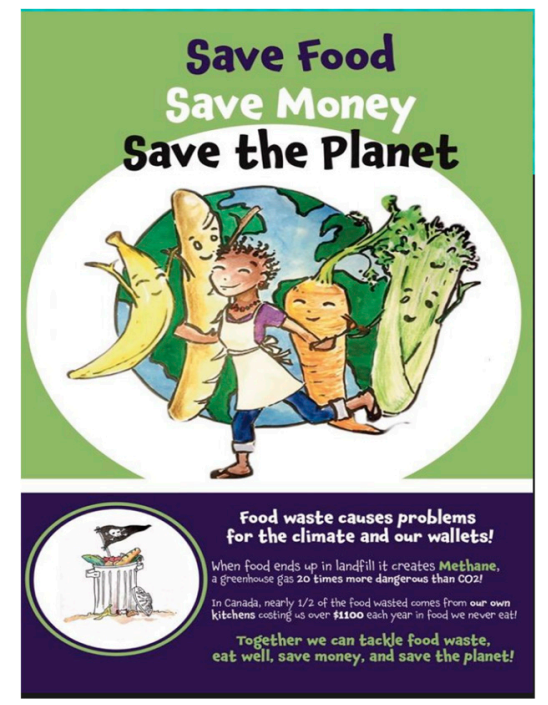

(a)

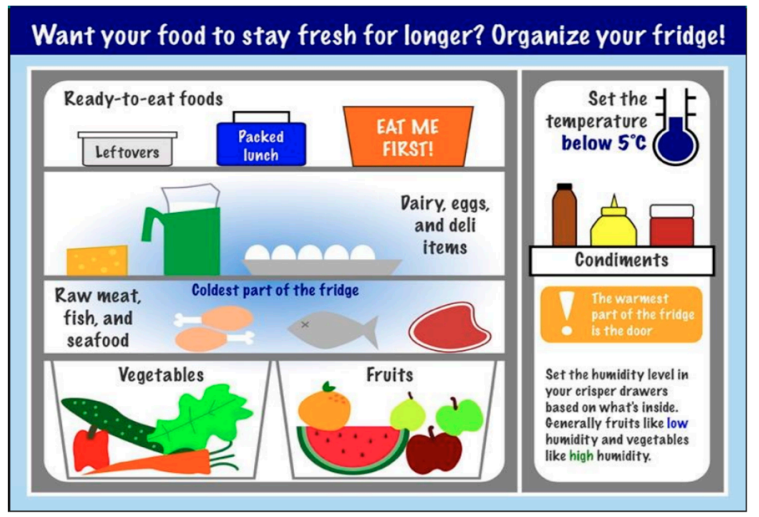

(b)

Figure 1. Informational booklet (a) and fridge magnet (b).

The third method was an information-based campaign augmented by an online game (the Game group). In addition to the information materials, participants were invited to play an online quiz game (see Figure 2) with points and rewards. There were five trivia questions each week about food waste as a problem and how to reduce food waste at home. Participants earned ten points per week (twelve-week game) for correct answers and were rewarded with a $\$ 20$ grocery gift card if they accumulated 120 points or a $\$ 10$ grocery gift card if they accumulated 60 points at the end of the 12 weeks. The game was pre-tested prior to delivery and several questions were modified to increase their clarity. The ethics protocol (\#36203) for this study was approved by the University of Toronto Social Sciences, Humanities, and Education Research Ethics Board on 1 June, 2018. 
Question 2/5

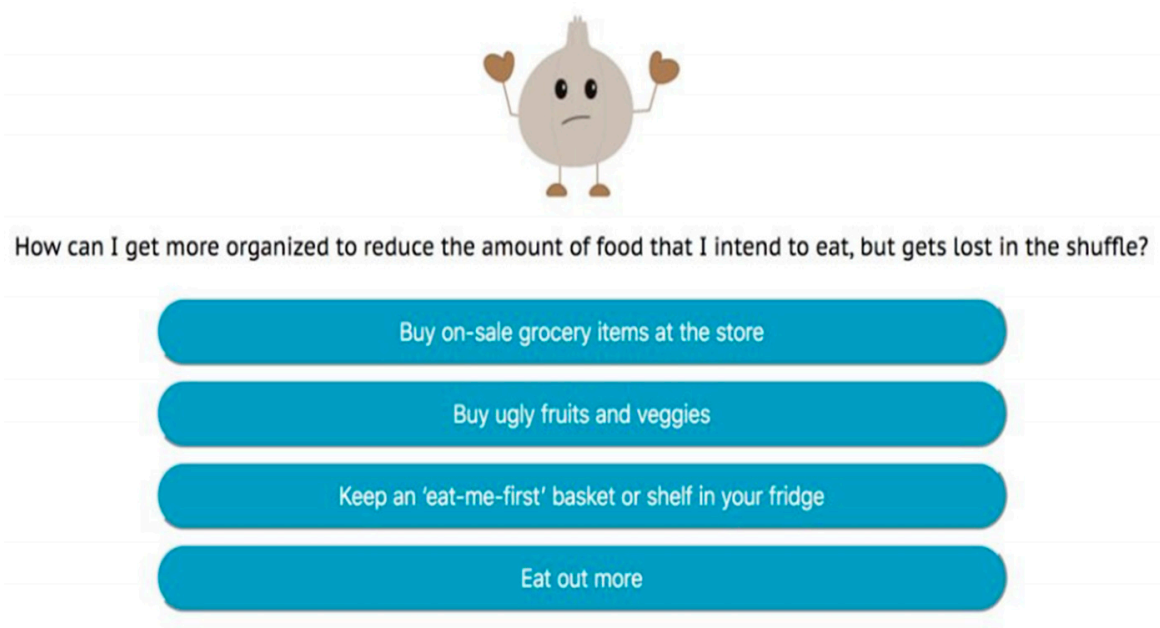

Figure 2. Sample online game question.

\subsection{Recruitment}

For each intervention group and the control group, participants were recruited from single-family homes and multi-family buildings. Since the study was also interested in disposal practices (although those findings are not reported here), it was important to understand how single-family homes compared to multi-family homes because of convenience and infrastructural differences. Multi-family homes tend to have fewer members per household than single-family homes, so recruiting from both groups was meant to ensure that we would capture both small and large households in the sample. Single-family homes were selected from the City of Toronto's residential curbside collection routes. All single-family households in the City of Toronto receive waste, recycling, and organic collections from the City. However, there is no guarantee that households separate their waste correctly and that contamination does not occur. Due to the existence of organic stream collection in the City, there is basic awareness about different waste streams, but not necessarily about the importance of food waste reduction.

With regards to collection, two routes from each of four collection days in the Scarborough administrative division were assigned to each group. For each route, a cluster of approximately 300 to 500 homes was randomly selected. Select demographic indicators (age distribution, language distribution, income distribution, and household size) for each cluster were gathered from neighbourhood census profiles to confirm that the selected clusters were representative of the diversity of residents in Toronto. The research team went door-to-door within the selected clusters to knock on doors to ask residents to participate. Residents that did not answer or were unsure about participating were given door hangers with contact information to sign up for the study. We did not return to homes with no response. The timing for recruitment took place from 2:30 p.m. to 8:00 p.m. on weekdays and 10:00 a.m. to 4:00 p.m. on Saturdays.

Recruitment of participants from multi-family buildings was more challenging than for single-family homes because it required permission of the building property manager. We contacted the property managers of 11 buildings in the city to ask whether they would be interested in participating in our study. Six declined or did not respond to our inquiry, while the remaining five gave us permission to recruit participants in the building lobby. The five buildings included one medium-income condominium, one low-income rental building, two graduate student rental buildings, and one co-op building. Recruitment took place in the building lobby or just outside of the building entrance over a two- to four-hour period. For two of the multi-residential buildings, recruitment coincided with a special community event at the building to increase the likelihood of encountering residents. Recruiters approached residents as they were entering or exiting the building, or in the case of the 
special events, while the residents were at the event by enquiring whether the resident lives in the building. A total of 501 participants were recruited, broken down as per Table 1. A flowchart of the study can be seen in Figure 3 for single-family households (note: Multi-family households had the same campaign treatment, with the difference being that waste audits were conducted for the entire building)

Table 1. Number of participants recruited.

\begin{tabular}{cccc}
\hline Participant Group & Multi-Family & Single Family & Total \\
\hline Control (Control) & 59 & 61 & 120 \\
Information (Info) & 90 & 50 & 140 \\
Information + Community Workshop (Community) & 60 & 59 & 119 \\
Information + Gamification (Game) & 60 & 62 & 122 \\
Total & 269 & 232 & 501 \\
\hline
\end{tabular}

\section{2-week campaign}

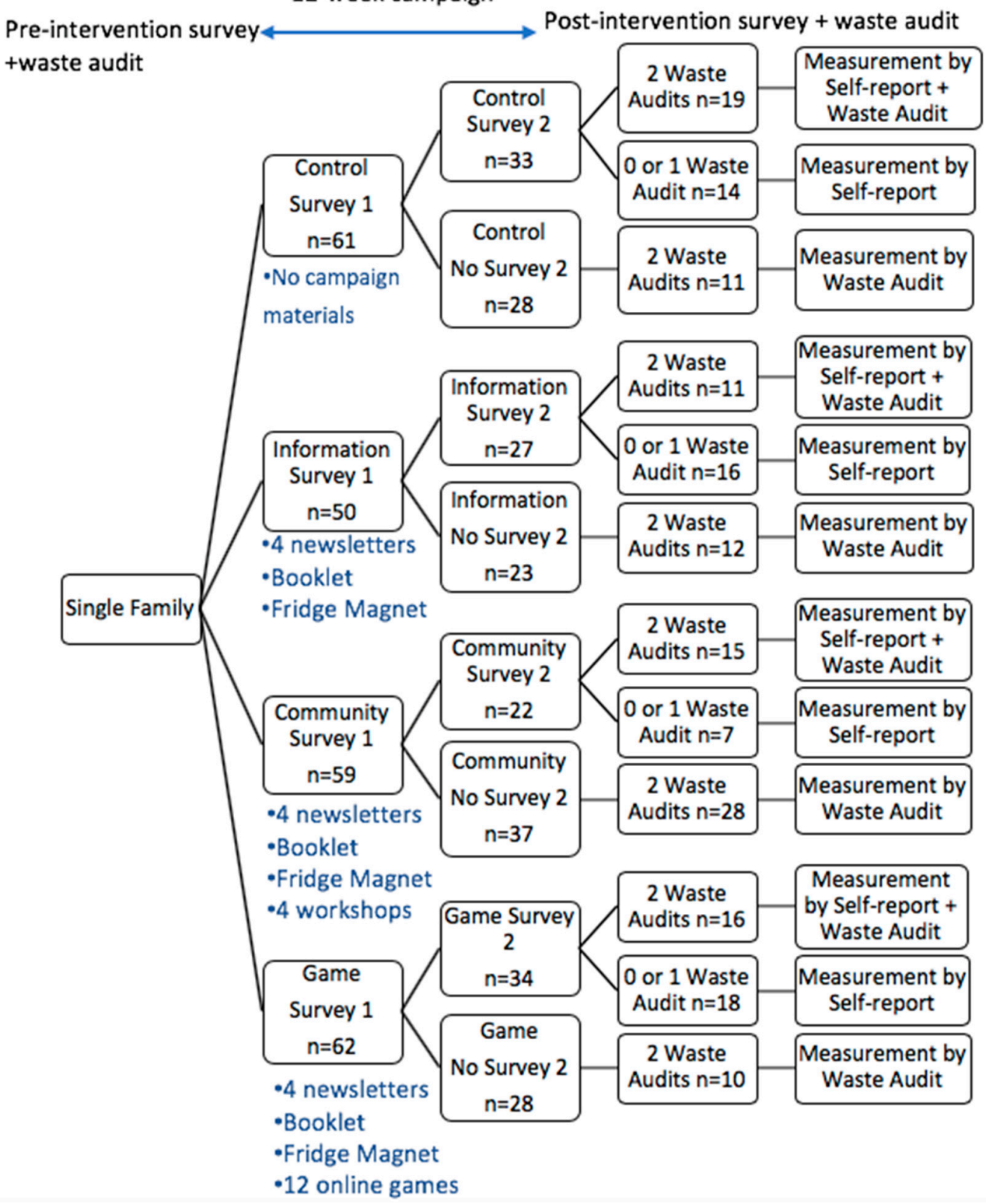

Figure 3. Flowchart of the study for single-family households. (Multi-family households experienced the same campaign format but waste audits were performed for buildings, not individual households.) 


\subsection{Waste Audits}

Waste audits were conducted before and after the twelve-week campaigns using the same methodology each time by housing type (see Supplementary Materials). For single-family homes, we collected the contents of garbage and organics bins set out at the curbside, with the exception of hazardous materials or bulky items that were unsafe to collect (e.g., broken glass, drywall, construction debris, medical waste). We sorted samples into primary categories of edible food waste, inedible food waste, and non-food waste. Samples were also aggregated and sorted into secondary categories by food type, but that data is not reported here. Pre-campaign, we collected samples from 164 single-family homes. Post-campaign, we collected samples from 146 single-family homes. The number of samples was smaller because not all of the pre-campaign households set out their garbage and organics at the post-campaign collection. The proportion of respondents in the demographic categories were not significantly different from each other (see Appendix B) based on Chi-square tests on each demographic variable, such as gender $(p=0.19)$, age $(p=0.27)$, household composition $(p=0.23)$, education $(p=0.83)$, and income $(p=0.69)$.

While we also conducted waste audits at multi-residential buildings, it is important to note that individual units of waste from participants who participated in the study could not be isolated for multi-family homes, as the bins had mixed waste from the entire building. The target sample size was $100 \mathrm{~kg}$ per building from garbage and organics (if applicable) compactors, dumpsters, or carts. However, all buildings had trash and/or organics chutes, making it difficult and often unsafe to fully sample the materials because waste was coming down the chute. Furthermore, the research team was given a narrow window of time within a one-day period at each building to access the waste areas for collection and sorting. Therefore, all the materials that could be safely collected were taken as samples, even if they were less than $100 \mathrm{~kg}$, due to hazards and bins that were not completely full. Due to the issues noted above, we will not be presenting the audit findings from the multi-residential audits.

\subsection{Surveys}

Recruited participants completed a survey before (Survey 1) and after (Survey 2) the interventions; each participant was awarded a $\$ 10$ grocery gift card for completing the survey. Survey 1 was conducted in person during recruitment. Survey 2 was conducted online for participants with email addresses, over the phone for those that provided a phone number but no email address, or by mail for participants that did not provide an email address or phone number. Survey 2 was sent out immediately after the completion of the 12 weeks. Gift cards for Survey 2 were mailed to the recipients immediately after the completion of the survey. Survey 1 asked about socio-demographics, as well as questions pertaining to food shopping, food waste management, food storage, knowledge about best-before dates, and reasons for wasting. Survey 2 asked the same questions, excluding the socio-demographics, and added questions about the use and helpfulness of the information materials, participation in the community workshops and the game, changes in awareness of food waste ("In the past three months, would you say your awareness of food waste has changed?") and perceived changes in food wasting behaviour ("In the past three months, how has the amount of food waste you throw away changed?"). In this paper, we are reporting only on the additional questions asked in Survey 2. As seen in Table 2, there was a considerable drop-off in response between Survey 1 and Survey 2, ranging from $67 \%$ of the original sample down to $33 \%$.

Table 2. Number of survey respondents.

\begin{tabular}{ccccc}
\hline \multirow{2}{*}{ Group } & \multicolumn{2}{c}{ Multi-Family } & \multicolumn{2}{c}{ Single Family } \\
\cline { 2 - 5 } & Pre & Post & Pre & Post \\
\hline Control & 59 & $36(61 \%)$ & 61 & $33(33 \%)$ \\
Information Only & 90 & $36(40 \%)$ & 50 & $27(54 \%)$ \\
Information + Community Workshop & 60 & $33(55 \%)$ & 59 & $22(37 \%)$ \\
Information + Online Game & 60 & $40(67 \%)$ & 62 & $34(55 \%)$ \\
\hline
\end{tabular}




\subsection{Focus Groups}

Selected participants in the Information, Community, and Game groups were invited to participate in a $1.5 \mathrm{~h}$ focus group about three months after the end of the campaigns. The objective of the focus groups was to gain a deeper understanding of issues not covered in surveys and that could not be explained in waste audits alone; specifically, barriers to food waste reduction despite increasing awareness. Forty-four participants attended the focus groups and chose a session on a Saturday or Sunday during daytime hours. The purpose of the focus group was to better understand the context of the behaviours and practices of the participants that could not be captured through the surveys. For example, we were interested in better understanding the utility of the interventions/tips/recommendations, which ones work best, and why. We were also interested in understanding barriers to participation, specifically with the Community group.

\subsection{Data Analysis and Limitations}

Weekly household food waste generation rates were approximated for single-family homes by adding together the amount of food waste measured in the green bin and half of the amount of food waste measured in the garbage bin due to the bi-weekly collection schedule for garbage. The number of samples collected before and after the campaign differed, as some residents only set out their bins for the pre-campaign waste audit but not the post-campaign audit and vice versa. There were 129 households that had set out garbage and/or organics bins for both waste audits. A limitation of this study is that the waste audit was limited to one week. Due to weekly variations in household waste, the statistical power of a one-week waste audit is less than that of a multi-week waste audit.

Weekly per capita food waste generation rates were calculated by dividing the weekly household food waste generation rate by the household size (sum of number of adults and number of children) reported in the survey. Survey respondents had the option to opt out of demographics questions, so the number of single-family waste audit samples with associated household sizes was 155 before the campaign and 122 after the campaign. For one household that reported their household size was "more than 8 adults", it was assumed that the number of adults was 10 for this calculation.

The weekly household food waste generation rates and weekly per capita food waste generation rates from the audits were tested for normality to determine the type of statistical test to use. Using the normal test function in SciPy, based on the D'Agostino-Pearson normality test, neither of the data sets was considered normally distributed ( $p<0.01$ for household and $p<0.01$ for per capita). Therefore, non-parametric methods were employed. For this study, we used an $\alpha$ value of 0.05 to define significance, with any $p$ values between 0.05 and 0.10 referred to as marginally significant.

Only nine people who participated in the community workshop responded to the second survey. The sample size was too small to conduct statistical tests to determine how the Community group fared compared to the control and other campaign groups on both self-reported behaviour and self-reported food waste awareness measures. Self-reported results are therefore given for the control, information, and gaming groups only.

\section{Results}

\subsection{Food Waste Quantities from Waste Audits}

The following results include data from single family homes that had curbside set outs both preand post-campaign and provided information about their household size in the survey. Figure 4 shows the total percentage of waste found in garbage bins and green bins by edible, inedible, and non-food waste categories. Examples of the food items found in the edible and inedible categories are provided in Appendix A. We acknowledge that the definition of edible is not fixed because of the diversity of eating norms related to parts of food [39,40]. For example, some people think that potato peels are inedible, and others think that they are edible. Generally, we used a more open definition, so if at least some people eat a part of a food "normally", then it was grouped as edible. 
Edible food waste comprised $37 \%$ of the combined garbage and green bin waste and $64 \%$ of all food waste. More than $40 \%$ of the edible food waste was fruits and vegetables. We did not have a large enough sample size to detect changes in the different types of edible food waste discarded pre- and post-campaign by campaign type compared to the control group, but we were able to test for changes in the weight of total edible food waste.

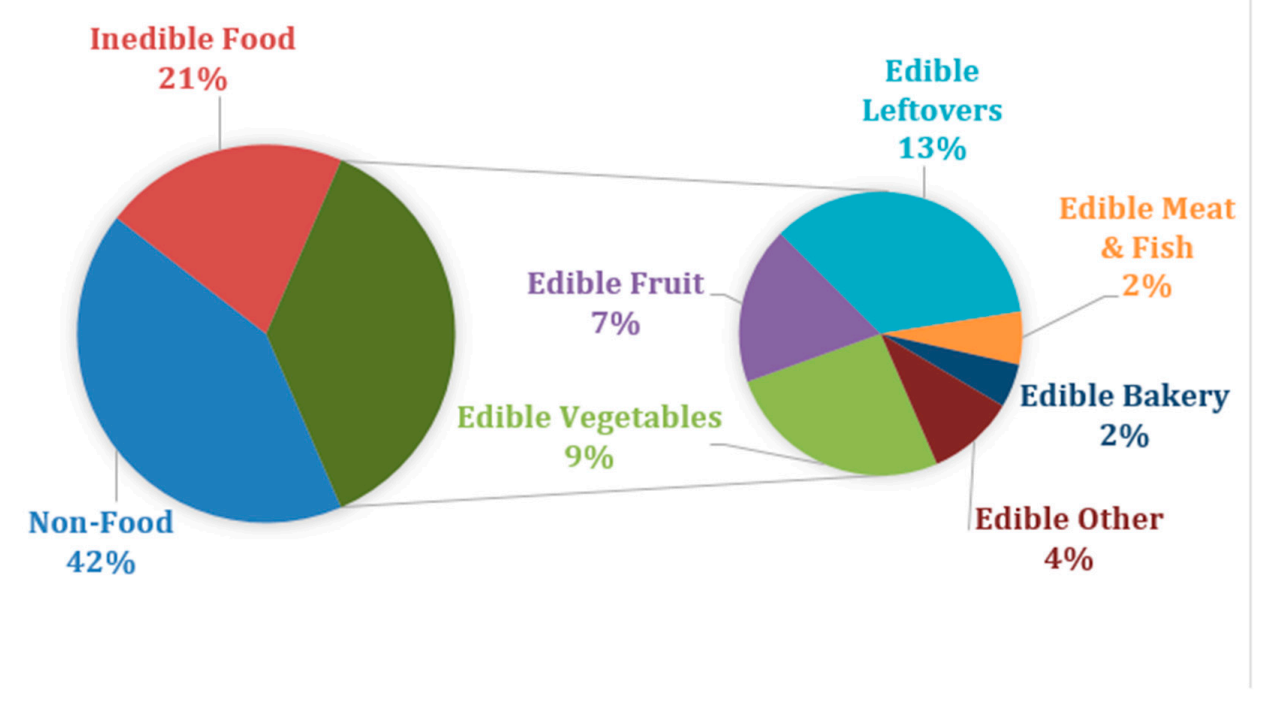

Figure 4. Average pre-campaign waste composition in garbage and green bin combined.

Pre-campaign, the average amount of edible food waste discarded by participant group ranged from 1.1 to $1.5 \mathrm{~kg} /$ week/person (Figure 5). The differences between participant groups were not statistically significant (Kruskal-Wallis: $p=0.84$ ). Post-campaign, the range was 0.9 to $1.3 \mathrm{~kg} /$ week $/$ person. Although the amount of food waste per capita per week produced by the Game group was about $30 \%$ lower than that produced by any of the other groups by the end of the campaign, there was no statistically significant difference in food waste changes across the groups (Kruskal-Wallis $\mathrm{H}=3.69, p=0.30$ ). Examining changes in the amount of food wasted within each group using a Wilcoxon Signed Rank test (one-tail test for the intervention groups and two-tail for the Control group), we found no significant differences in pre- and post-campaign food waste in the Control ( $\mathrm{z}=-0.70, p=0.48)$, Information $(\mathrm{z}=-0.37, p=0.36)$, and Community $(\mathrm{z}=-0.188, p=0.43)$ groups. The Game group exhibited a marginally significant decrease $(\mathrm{z}=-1.47, p=0.07)$.

To gain an understanding of differences in food waste thrown out by participants in a campaign compared to non-participants, we examined the single-family Game group waste audit results more closely. We divided the group into those that played the most, namely 11-12 weeks, versus the rest of the Game group. We found that there was no statistically significant difference between the two groups in the amount of food wasted before the campaign, but there was after the campaign ended: The high-frequency participants were found to be wasting less food than the lower-frequency participants by the end of the campaign and had decreased their waste by about $50 \%$ (Table 3).

Table 3. Audit results for frequent and infrequent game players.

\begin{tabular}{ccc}
\hline Weeks Game Played & Audit 1 (kg/week/person) & Audit 2 (kg/week/person) \\
\hline Frequent: 11-12 weeks $(n=14)$ & 1.37 & 0.67 \\
Infrequent: 0-10 weeks $(n=12)$ & 1.64 & 1.00 \\
Mann Whitney U between Frequent & $p=0.200$ & $p=0.030$ \\
and Infrequent Game players & & \\
\hline
\end{tabular}




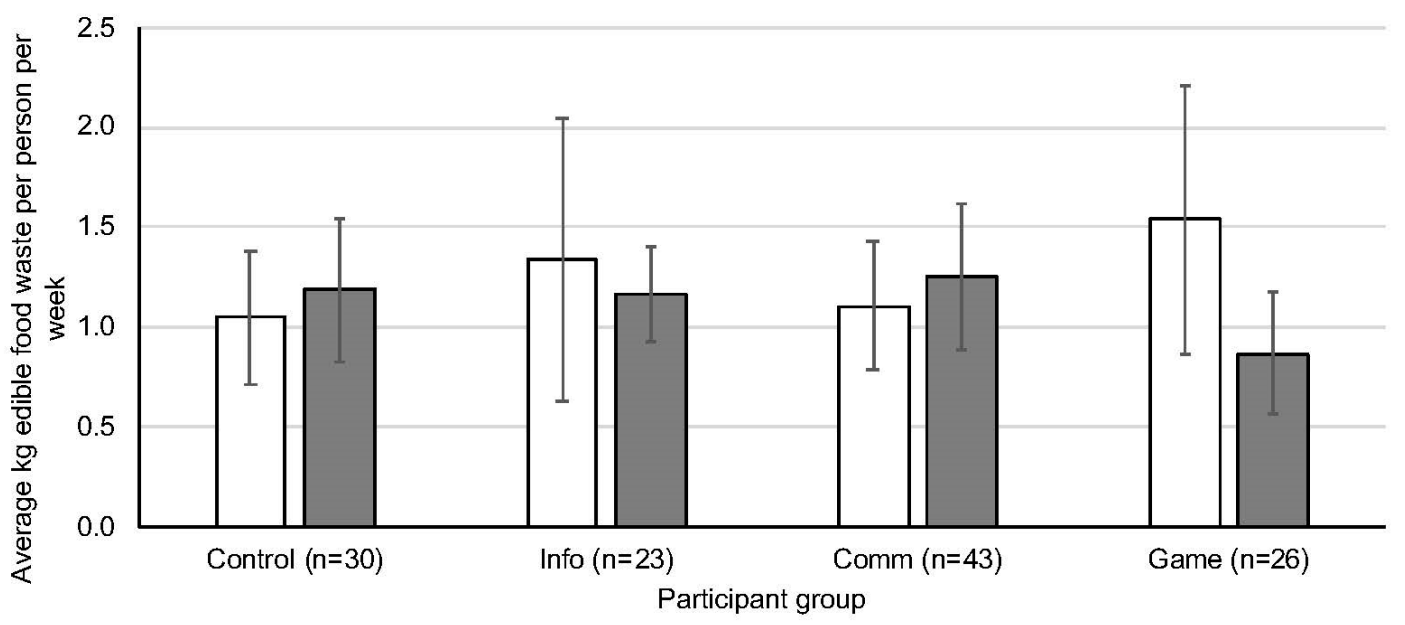

口Pre-Campaign aPost-Campaign

Error bars denote $95 \%$ confidence intervals.

Figure 5. Edible food waste pre- and post-campaign.

\subsection{Campaign Participation Rates}

\subsubsection{The Information Campaign Group}

All but $16 \%$ of the Information group members used at least one of the information resources provided during the campaign. We found that the majority of participants (57\%) used the fridge magnet. The use rates of the booklet (34\%) and four newsletters (18\% to 38\%) were lower. Use rates of the three kinds of information materials by members of the Information group were found to be not statistically significantly different from the use rates in either the Community group or the Game group for the fridge magnet $\left(\chi^{2}=1.47, p=0.48\right)$, booklet $\left(\chi^{2}=0.49, p=0.78\right)$, newsletter $1\left(\chi^{2}=4.49\right.$, $p=0.11)$, newsletter $2\left(\chi^{2}=1.57, p=0.45\right)$, and newsletter $3\left(\chi^{2}=0.04, p=0.98\right)$. There was a marginally significant difference in use rates for newsletter $4\left(\chi^{2}=5.19, p=0.07\right)$, with $32 \%$ of the Game group members using it compared to $18 \%$ for the Information group and $19 \%$ for the Community group, perhaps because the ongoing information demands of the game stimulated greater use.

Participants in the focus groups explained that the magnet was particularly useful because it helped them reorganize their food storage in the fridge. For example, Gabriela (all participants below are identified by pseudonyms) said that

"I really like the magnet. I still have it on our fridge and what I like is that when people come to our apartment, they usually see the magnet as well, so it's not even just us but others who see ... it was useful because it actually taught us how to organize our fridge. Even though we do not have that much waste, it was good to know the correct way of organizing the fridge because you actually don't know."

Participants in the focus group also explained why the online newsletters and tips from the booklet were not as useful. Information fatigue and being overwhelmed with too much information and emails was a common theme. For example, Grace remarked that

"I'd just say maybe there was a lot of education materials and that was like so much information to sort through, and I kind of tuned out the emails to be honest ... I did read the booklet, like I looked through that, but kind of like put it away so it's not like I saw that very much. So yeah, I would occasionally look at the newsletter but like I said I don't always read my emails. It's tricky, like reaching people is hard because we get so much information thrown at us all the time."

\subsubsection{The Community Workshop Group}

For the Community group, only seven single-family residents attended workshops and six of the invited multi-family residents attended. There were four workshops held for the multi-family 
households and four workshops held for the single-family households, for a total of eight workshops. In three out of the eight workshops, only one household showed up. In some cases, participants would bring their spouse, a friend from their community, or young children to the event (since we provided childcare). However, because only those answering the surveys are those who consented to participate in this study and their spouses are not technically part of the study-even though a spouse may contribute to food waste management, generation, prevention, and reduction - they are not included in the sample. Through the survey, we found that nine out of 56 respondents in the Community group said that they attended at least one event, i.e., $16 \%$. Note that this only reflected survey respondents and not all of the people in this group. There may have been respondents who attended a community event but did not respond to the survey or people who did not attend an event and said they did. For the nine people who answered that they attended the community engagement event on Survey 2 , most reported in an open-ended answer which was coded by the research team that they learned about the environmental impact of food waste and composting (see Table 4).

Table 4. Community workshop learnings.

\begin{tabular}{cc}
\hline Learnings & Number of Responses \\
\hline Best-before dates & 2 \\
Growing produce & 1 \\
Environmental impact of food waste + composting & 6 \\
Meal planning & 1 \\
Storage techniques & 2 \\
Recipes & 2 \\
Nothing & 2 \\
\hline
\end{tabular}

Respondents to the survey who said that they did not attend any of the community engagement events provided the following reasons, with the highest being issues concerning scheduling conflicts (Table 5).

Table 5. Community workshop absences.

\begin{tabular}{cc}
\hline Reasons for Not Attending the Community Workshop & Percentage (n = 47) \\
\hline Scheduling conflict & $47 \%$ \\
Childcare & $21 \%$ \\
Busy (no reason provided) & $17 \%$ \\
Did not receive info & $9 \%$ \\
Did not see the need & $6 \%$ \\
Other & $6 \%$ \\
No reason & $4 \%$ \\
\hline
\end{tabular}

Through the focus group, we had a better insight about why community engagement was low. Two themes arose from the focus group: Time scarcity (busy) and information fatigue,

Ali: "I think it's again going back to the fatigue. There are a million videos on YouTube, DIYs [referring to do-it-yourself videos] ... maybe the messaging and marketing made it seem that it does not matter, there's nothing new."

Gabriela: "Yeah, I remember I saw that email, but I'm doing my BA and I said no way because of the timing. Now that you ask the question, if it was recorded like in a short online course, it would definitely be something that I would watch maybe during the weekend, like 10 min." 


\subsubsection{Gamification Group}

The participation rate in the Game group was substantially higher than in the Community group. For the Game group, $61 \%$ of participants answered in Survey 2 that they played all 12 levels of the game. Across 12 weeks, the average game participation rate was 53\%. As shown in Figure 6, participants appeared to either be heavily engaged in the game ( $25 \%$ played all 12 weeks, $16 \%$ played 11 weeks), or did not engage at all with the game (36\% played zero weeks). Of those that did not play the game at all, $23 \%$ did not have email addresses or gave incorrect email addresses and therefore could not be reached. In the survey, participants noted that the most common barriers identified by participants for not playing the game were not receiving game information/reminders or forgetting about the reminder $(56 \%)$ and being too busy or not having time ( $25 \%)$. In the focus group, participants in the Game group highlighted their interest in the game. Several themes were noted by the participants, namely that the game was quick to do, simple, and fun. Focus group participants also noted that the weekly game reminders acted as nudges to keep them on track with waste reduction and that they found themselves sharing the game with other household members:

Kristina: "One factor that made me play them was that they were doable and not hours long. I learned new things with the game and remembered questions."

Susan: "Playing on your phone and tablet is much easier. The other thing is that you get reminded about the behaviour of reducing food every week even if you don't remember the numbers necessarily and the handouts ... you start to keep track of what you are doing."

Sherry: "I would get kind of upset when I got a wrong answer or something. Call my husband, say come here, what do you think of this? ... So yeah, it was good. I enjoyed it very much. I was sorry when it ended, I really was."

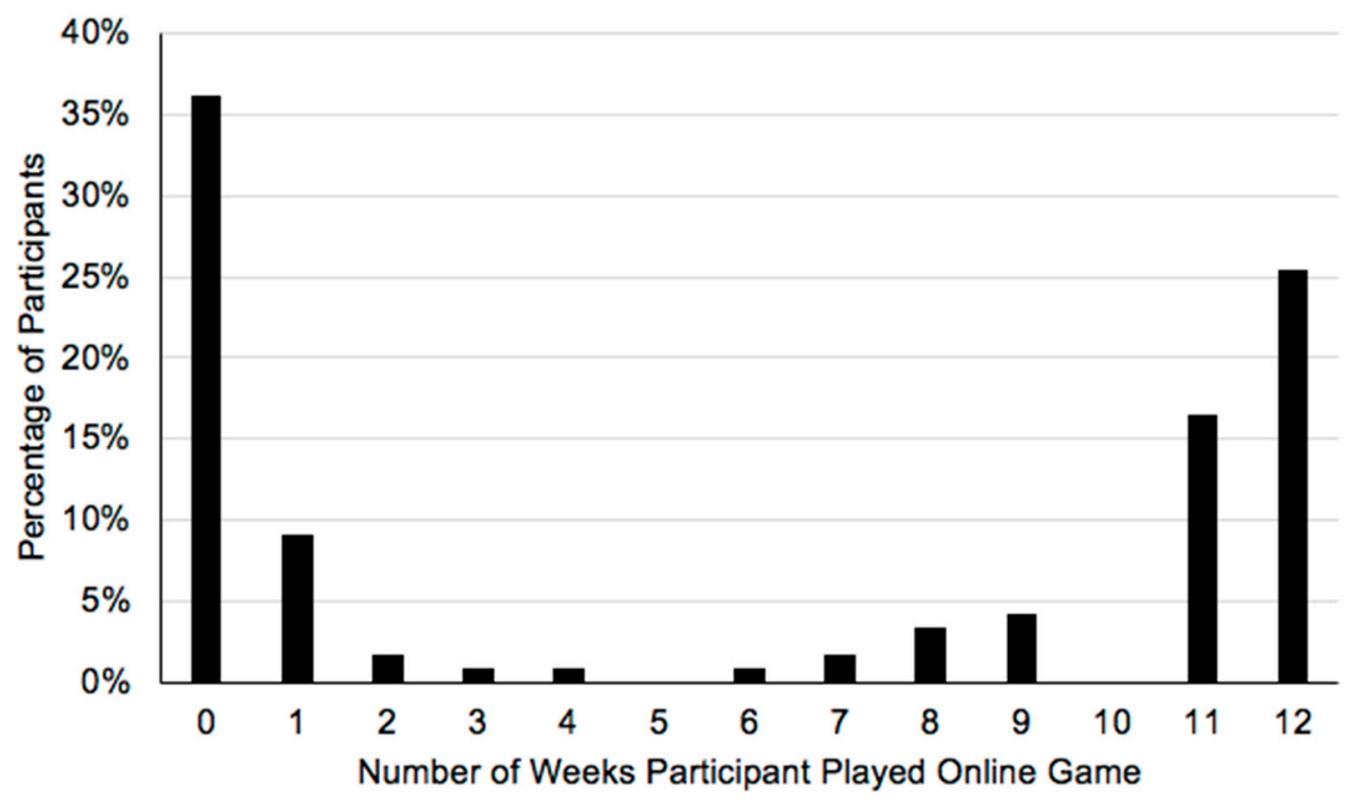

Figure 6. Game participation rates.

When using an online-based game as an intervention, it is critical that the participants provide correct email addresses or have easy access to internet. For the most part, the 16 participants who did not play the game noted that they did not receive the info/reminder/had forgotten $(n=9)$, with the second highest reason being busy/no time $(n=4)$, followed by complaints that it was not user friendly $(\mathrm{n}=2)$ and that there were language barriers $(\mathrm{n}=1)$. 
In summary, participation rates in the Information group were high, in the Community group they were very low, and they were relatively high in the Game group. Time and availability were the most serious problems affecting participation in the Community group, which suggests that widespread use of this type of campaign is unlikely to reach a large portion of the target population. The participation rates for the other two types of campaigns are considerably more encouraging.

\subsection{Changes in Self-Reported Food Wasting}

Although the waste audit results did not find a difference among the three campaign groups, that was not the case for the self-reported survey results. Table 6 shows the results for the Information and Game groups of changes in food wasting for participants over the three-month period of the campaigns. Unlike the waste audit data, the campaign group results reported below include only those who said that they participated in a campaign-i.e., for the Information group, only those who said in Survey 2 that they used at least one of the information resources provided, and for the Game group, only those who said that they participated in at least one game. There is a statistically significant difference between the Control group and the Information group and between the Control group and the Game group. Participants in the two campaign groups reported throwing out less waste in the past three months than participants in the Control group. There is no difference between the amount of food waste thrown out by the Information and Game groups.

Table 6. "In the past three months, has the amount of food you throw out changed?"

\begin{tabular}{cccc}
\hline & $\begin{array}{c}\text { Control } \\
(\mathbf{n}=\mathbf{6 9 )}\end{array}$ & $\begin{array}{c}\text { Information } \\
(\mathbf{n}=\mathbf{5 3})\end{array}$ & $\begin{array}{c}\text { Gaming + Information } \\
(\mathbf{n}=\mathbf{6 0})\end{array}$ \\
\hline Decreased a lot & $8.7 \%$ & $24.5 \%$ & $23.3 \%$ \\
Decreased a little & $21.7 \%$ & $34.8 \%$ & $51.7 \%$ \\
Stayed about the same & $69.6 \%$ & $39.6 \%$ & $25.0 \%$ \\
Mann Whitney U Campaign vs. Control & & $p=0.001$ & $p=0.000$ \\
Mann Whitney U Campaign vs. Campaign & & & $p=0.311$ \\
\hline
\end{tabular}

An example of the impact that the information resources had on participants came from Nina in the Game group, who said that she has decreased her food waste a lot and that the tip about sorting food waste in the fridge has helped her do this:

"We used to have vegetables that would go bad before we could get to them because I'd forget about them in the little crisper drawer. So, what I've been trying to do is cause you've got two drawers, the new stuff goes in the right and the stuff that I've had for a little bit goes in the left so I can try to keep tabs on it. It's really helped a lot."

\subsection{Changes in Self-Reported Awareness of Food Waste}

Survey respondents were asked whether their awareness of food waste had changed over the period of the campaign. The results (Table 7) show a statistically significant difference between the Control group and the Information group and between the Control group and the Game group for this question. Awareness of food waste increased more in the two campaign groups in comparison to the Control group. There is no difference in change in awareness between the Information group and the Game group.

A large percentage of participants $(44 \%)$ in the Control group reported a change in awareness of food waste even though they were not exposed to any of the campaigns. It is possible that just by being involved in a food waste research study, the Control group's awareness was raised. It is also possible that factors external to the study raised awareness, such as food waste news in the media during the three months of the study. 
Table 7. "In the past three months, would you say your awareness of food waste changed?"

\begin{tabular}{cccc}
\hline & $\begin{array}{c}\text { Control } \\
(\mathbf{n = 6 9 )}\end{array}$ & $\begin{array}{c}\text { Information } \\
(\mathbf{n}=53)\end{array}$ & $\begin{array}{c}\text { Gaming + Information } \\
(\mathbf{n}=\mathbf{6 1})\end{array}$ \\
\hline Increased & $43.5 \%$ & $73.5 \%$ & $86.9 \%$ \\
No, already very conscious of food waste & $44.9 \%$ & $24.5 \%$ & $13 \%$ \\
No, food waste not important to me & $11.6 \%$ & $1.9 \%$ & $0 \%$ \\
$\chi^{2}$ Campaign vs. Control & & $p=0.007$ & $p=0.000$ \\
$\chi^{2}$ Campaign vs. Campaign & & & $p=0.281$ \\
\hline
\end{tabular}

\section{Discussion and Conclusions}

This study examined the effectiveness of three kinds of information delivery campaigns designed to raise awareness among households about the issue of food waste and encourage them to reduce their food waste. We hypothesized that the campaigns would perform better than a control group in raising awareness and reducing waste and measured performance in three ways: Self-reported assessments of changes in food waste awareness and food wasting practices, and audits of household food waste.

All three of our hypotheses contend that the campaign groups will throw out less edible food waste after the campaign than the control group. Our finding is that only the gamification group had a marginally significant result in terms of less edible food waste after the campaign $(p=0.07)$. A qualification on this finding is that the three campaign groups include households that participated in their group campaign and those that did not. However, we felt that it was important to include all campaign group members, even those who reported that they did not participate in the campaign, in order to illustrate the effectiveness of a specific campaign, taking into account non-participation by the target group. In the program evaluation literature, including non-participants when calculating the average effect of an intervention on a population is referred to as the average treatment effect (ATE), while excluding non-participants is referred to as the average treatment-on-the-treated effect (ATT) [41]. If participation in the game had been higher, the finding of marginally significant results in post-intervention waste quantities between the Control group and the Game group might have been statistically significant. We found that those in the Game group who played the game every week or almost every week generated a significantly lower amount of avoidable food waste compared to those who played less frequently or not at all $(p=0.030)$.

With respect to participation, we found that the Information group attained the highest participation levels, followed by the Game group with slightly lower participation. Participation in the Community group was deemed too low to make it a feasible, widespread delivery method for food waste campaigns. The self-reported data on changes in food waste awareness and food wasting found that the Information group and the Game group had higher awareness of food waste than the Control group after the campaign, as well as lower self-reported food wastage. There was no difference between the Information group and the Game group on this measure. Recognizing that self-reported data on food waste behaviour changes may over-estimate actual behaviour changes, these results still illustrate the success of the Information and Game campaigns in increasing awareness of food waste.

This study is the first to report on the use of gamification as a behaviour change tool for reducing food waste. The results are mixed as shown above, and are consistent with previous research about the role of information in influencing pro-environmental behaviour. Recent reviews of food waste behaviour emphasize the need to consider how the routines of everyday life constrain the ability of households to respond to information campaigns [42]. In terms of research transferability, it is important to note that the City of Toronto has a green bin (organic waste) program and regular waste pick up. This means that the respondents have some basic awareness of food wastage because of the need to source-separate their waste. Consequently, the transferability of these interventions would likely differ where there is a lack of municipal waste pick up (e.g., low-income countries) or no source separation of organic waste to begin with. Qi and Roe [43] found that when participants receive awareness interventions at an "all you can eat buffet", food waste was significantly reduced (77\%). However, when 
patrons received information that the food waste would be composted, reduction level dropped $(28 \%)$. This drop may reflect a licensing behavior, as composting is seen as a sustainable practice and it may work against the efficacy of interventions that are focused on food waste reduction [43]. In the context of Toronto, an organic waste program is established across the City and may create a licensing effect for participants to not focus on reduction. Despite the presence of an organic waste source-separation program, considerable amounts of food waste $(47 \mathrm{~kg} /$ household/year) are still disposed of in garbage and $74 \%$ of that is edible/avoidable food waste [44].

Even though the results of this study are mixed, we feel that they are sufficiently encouraging to recommend further exploration of gamification's effectiveness in achieving food waste reduction. In particular, we note that frequent gamers were found to generate less edible food waste than less frequent gamers. Future research would benefit from a larger sample size, since the sample size of the Game group for the food waste audits was relatively small at 26 households. Second, new research should examine how to make this type of game more economically sustainable by switching from monetary rewards to those that are non-monetary, such as leaderboards and others listed by Hamari et al. [37], Johnson [38], and Johnson et al. [36]. Third, further study could assess whether the design of the game affects take-up and effectiveness. The game used for this study was relatively simple in its design with no interactive links and little animation. Fourth, the question of whether gamification affects longer-term food wasting behaviour should also be examined. Although evidence is limited, Johnson [38] found that reward-based gamification, at least in the field of energy consumption, may not have lasting effects and needs further research. Finally, the content of the game could be tested to determine what type of food waste messaging works best with gamification strategies.

Supplementary Materials: The following are available online at http://www.mdpi.com/2071-1050/12/3/907/s1, Waste Audit Data.

Author Contributions: Conceptualization, T.S., B.L., and V.M.; methodology, T.S. and B.L.; formal analysis, B.L., V.M, and T.S.; writing — original draft, T.S.; writing — review and editing, T.S, B.L., and V.M.; project administration, T.S.; funding acquisition, T.S., V.M, and B.L. All authors have read and agreed to the published version of the manuscript.

Funding: We gratefully acknowledge funding from George Weston Ltd. and Loblaw Companies Ltd. through the Seeding Food Innovation Grant program.

Conflicts of Interest: The authors declare no conflicts of interest. The funders had no role in the design of the study; in the collection, analyses, or interpretation of data; in the writing of the manuscript, or in the decision to publish the results.

\section{Appendix A}

Table A1. Edible and inedible food waste examples.

\begin{tabular}{|c|c|c|c|}
\hline Category & Description & Edible Food Waste Examples & Inedible Food Waste Examples \\
\hline $\begin{array}{l}\text { Vegetables and } \\
\text { Salad }\end{array}$ & $\begin{array}{l}\text { Vegetables according to culinary } \\
\text { definition. Includes mushrooms and } \\
\text { fungi, roots and tubers, pulses and } \\
\text { legumes, and seaweeds. }\end{array}$ & $\begin{array}{l}\text { Eggplant, bean, broccoli, cabbage, } \\
\text { carrot (including peel), cauliflower, } \\
\text { celery, zucchini, cucumber, lettuce, } \\
\text { mushroom, onion, pea, pepper, } \\
\text { potato (including peel), spinach, } \\
\text { sprouts, squash, corn, tomato, salad } \\
\text { mix, mixed vegetables. }\end{array}$ & $\begin{array}{l}\text { Tops of root vegetables (e.g., } \\
\text { carrots), onion skin, hard stalks } \\
\text { (e.g., pepper, lettuce, squash), } \\
\text { hard vegetable peels (e.g., } \\
\text { winter squash). }\end{array}$ \\
\hline Fruit & Fruit according to culinary definition. & $\begin{array}{l}\text { Apple (including peel), banana, } \\
\text { kiwi, melon, orange, pear (including } \\
\text { peel), pineapple, mango, grapes, } \\
\text { berries, stone fruits, citrus fruits, } \\
\text { avocado, mixed fruits. }\end{array}$ & $\begin{array}{l}\text { Apple core, banana peel, } \\
\text { hard/waxy fruit peels (e.g., } \\
\text { melon, mango), vines (e.g., } \\
\text { grape or berries), citrus peel, } \\
\text { stone fruit pits, avocado peel } \\
\text { and seed. }\end{array}$ \\
\hline
\end{tabular}


Table A1. Cont.

\begin{tabular}{|c|c|c|c|}
\hline Category & Description & Edible Food Waste Examples & Inedible Food Waste Examples \\
\hline Meat and Fish & $\begin{array}{l}\text { All types of meat, poultry, and game } \\
\text { products, in pieces and cuts or } \\
\text { comminuted, fresh, and processed. } \\
\text { Includes fresh fish and various } \\
\text { processed fish products. Includes } \\
\text { aquatic vertebrates (fish and aquatic } \\
\text { mammals), aquatic invertebrates, and } \\
\text { shellfish. }\end{array}$ & $\begin{array}{l}\text { Pork, ham, bacon, beef, lamb, } \\
\text { chicken, turkey, duck, game meat, } \\
\text { deli meats, processed meats, fish, } \\
\text { jellyfish, clams, snails, shrimp, crab, } \\
\text { lobster, sea urchins, sea cucumbers. }\end{array}$ & $\begin{array}{l}\text { Bones, shells, tendon, fat from } \\
\text { cuts of meat. }\end{array}$ \\
\hline Bakery & $\begin{array}{l}\text { All savory baked goods and breads. } \\
\text { Includes uncooked dough or batter. } \\
\text { Does not include sweet bakery items } \\
\text { and processed snack foods. }\end{array}$ & $\begin{array}{l}\text { Bread, bagels, scones, soft pretzels, } \\
\text { croissants, pancakes, naan, filo, } \\
\text { tortilla, breadsticks, dough, pancake } \\
\text { batter, croutons, crisp breads, } \\
\text { breadsticks, breadcrumbs. }\end{array}$ & None. \\
\hline Dairy/Eggs & $\begin{array}{l}\text { Dairy products that are derived from } \\
\text { the milk of any milking animal (e.g., } \\
\text { cow, sheep, goat, buffalo). Fresh in-shell } \\
\text { eggs, products that may substitute for } \\
\text { fresh eggs, and other egg products. } \\
\text { Does not include ice cream. }\end{array}$ & $\begin{array}{l}\text { Milk, cheese, cream, yogurt, kefir, } \\
\text { sour cream. }\end{array}$ & $\begin{array}{l}\text { Egg shell, wax coating on } \\
\text { cheese. }\end{array}$ \\
\hline $\begin{array}{l}\text { Prepared Foods } \\
\text { and Leftovers }\end{array}$ & $\begin{array}{l}\text { Foods prepared as meals or components } \\
\text { of meals that are mixtures of multiple } \\
\text { categories of food. These include } \\
\text { pre-prepared foods which require } \\
\text { minimal preparation by the consumer } \\
\text { (e.g., heating, thawing, rehydrating). } \\
\text { Includes products composed primarily } \\
\text { of protein that are derived from } \\
\text { soybeans or from other sources. }\end{array}$ & $\begin{array}{l}\text { Soup, canned soup, stew, sandwich, } \\
\text { pasta with sauce, stir fry with meat } \\
\text { and vegetables, salad with dressing, } \\
\text { instant noodles, savory pie, burrito, } \\
\text { casserole, soy burger patty, frozen } \\
\text { dinner. }\end{array}$ & None. \\
\hline Desserts & $\begin{array}{l}\text { All sweet items that could be consumed } \\
\text { at the end of a meal or a snack. Includes } \\
\text { sweet bakery items. }\end{array}$ & $\begin{array}{l}\text { Cake, cheesecake, pudding, jelly, } \\
\text { donut, sweet pastries, sweet pies, } \\
\text { strudel, fruit crumble, ice cream, } \\
\text { mousse. }\end{array}$ & None. \\
\hline Staples & $\begin{array}{l}\text { Unprocessed and various processed } \\
\text { forms of cereal and cereal-based } \\
\text { products. Includes cooked cereal-based } \\
\text { products if they have not been mixed } \\
\text { with other types of food. }\end{array}$ & $\begin{array}{l}\text { Breakfast cereal, flour, pasta, rice, } \\
\text { corn flour, noodles, couscous. }\end{array}$ & Husks from milling. \\
\hline $\begin{array}{l}\text { Condiments/ } \\
\text { Sauces/Spices }\end{array}$ & $\begin{array}{l}\text { Substances added to food to enhance its } \\
\text { aroma and taste. Includes certain } \\
\text { prepared foods that act as sauces or } \\
\text { condiments. }\end{array}$ & $\begin{array}{l}\text { Salt and salt substitutes, soy sauce, } \\
\text { herbs, spices, seasonings, vinegar, } \\
\text { mustard, ketchup, salsa, } \\
\text { mayonnaise, gravy, dips, pickles, } \\
\text { olives, sugar, honey, jam, peanut } \\
\text { butter. }\end{array}$ & None. \\
\hline Oil/Fat & $\begin{array}{l}\text { All fat-based products that are derived } \\
\text { from vegetable, animal, or marine } \\
\text { sources, or their mixtures. Does not } \\
\text { include fat from cuts of meat. }\end{array}$ & $\begin{array}{l}\text { Butter, margarine, lard, suet, } \\
\text { vegetable oils, flavoured oils. }\end{array}$ & None. \\
\hline $\begin{array}{l}\text { Candy and } \\
\text { Snacks }\end{array}$ & $\begin{array}{l}\text { All cocoa and chocolate products, other } \\
\text { candy products, chewing gum, and } \\
\text { decorations and icings. All types of } \\
\text { savory snack foods, nuts, and seeds. }\end{array}$ & $\begin{array}{l}\text { Chocolate, candy, chewing gum, } \\
\text { cereal bar, cookies, nuts, seeds, trail } \\
\text { mix, popcorn, chips, crackers. }\end{array}$ & Nut and seed shells. \\
\hline Drinks & $\begin{array}{l}\text { Alcoholic and non-alcoholic beverages, } \\
\text { excluding dairy products. }\end{array}$ & $\begin{array}{l}\text { Bottled water, soft drinks, coffee, } \\
\text { fruit juice, tea, alcohol, smoothies. }\end{array}$ & Coffee grounds, tea bags. \\
\hline Other & $\begin{array}{l}\text { Items that do not fit into other categories } \\
\text { or serve a special purpose. Includes } \\
\text { items that are indistinguishable. }\end{array}$ & $\begin{array}{l}\text { Baby food, baby formula, mixed } \\
\text { semi-solid food, draining from } \\
\text { canned and bottled food. }\end{array}$ & None. \\
\hline Non-Food & $\begin{array}{l}\text { Anything that is not food or an inedible } \\
\text { part of food. }\end{array}$ & N/A & N/A \\
\hline
\end{tabular}




\section{Appendix B}

Table A2. Respondents based on demographic characteristics for single family households.

\begin{tabular}{|c|c|c|c|c|c|c|c|}
\hline & Control & Info & Comm & Game & Total & Chi2 Test & $p$ Value \\
\hline Gender & $(n=59)$ & $(n=50)$ & $(\mathrm{n}=57)$ & $(\mathrm{n}=61)$ & & & \\
\hline Male & $42 \%$ & $24 \%$ & $41 \%$ & $36 \%$ & $36 \%$ & & \\
\hline Female & $58 \%$ & $76 \%$ & $59 \%$ & $64 \%$ & $64 \%$ & 4.77 & 0.19 \\
\hline Age & $(n=56)$ & $(n=49)$ & $(\mathrm{n}=57)$ & $(\mathrm{n}=61)$ & & & \\
\hline $18-34$ & $30 \%$ & $20 \%$ & $23 \%$ & $20 \%$ & $23 \%$ & & \\
\hline $35-64$ & $34 \%$ & $49 \%$ & $56 \%$ & $54 \%$ & $48 \%$ & & \\
\hline $65+$ & $36 \%$ & $31 \%$ & $21 \%$ & $26 \%$ & $28 \%$ & 7.6 & 0.27 \\
\hline \multicolumn{8}{|l|}{ HH Size } \\
\hline $\mathrm{HH} 1$ & $2 \%$ & $2 \%$ & $9 \%$ & $5 \%$ & $5 \%$ & & \\
\hline $\mathrm{HH} 2$ & $24 \%$ & $29 \%$ & $16 \%$ & $32 \%$ & $25 \%$ & & \\
\hline HH 3+ & $75 \%$ & $69 \%$ & $75 \%$ & $63 \%$ & $70 \%$ & 8.17 & 0.23 \\
\hline \multicolumn{8}{|l|}{ Number of Children } \\
\hline None & $55 \%$ & $67 \%$ & $47 \%$ & $56 \%$ & $56 \%$ & & \\
\hline $1+$ & $45 \%$ & $33 \%$ & $53 \%$ & $44 \%$ & $44 \%$ & 3.97 & 0.26 \\
\hline \multicolumn{8}{|l|}{ Total } \\
\hline High School or Less & $25 \%$ & $23 \%$ & $27 \%$ & $20 \%$ & $24 \%$ & & \\
\hline Post-Secondary & $75 \%$ & $77 \%$ & $73 \%$ & $80 \%$ & $76 \%$ & 0.89 & 0.83 \\
\hline \multicolumn{8}{|l|}{ Total } \\
\hline$<\$ 40 \mathrm{~K}$ & $6 \%$ & $13 \%$ & $16 \%$ & $5 \%$ & $11 \%$ & & \\
\hline$\$ 40 \mathrm{~K}-\$ 100 \mathrm{~K}$ & $42 \%$ & $40 \%$ & $44 \%$ & $47 \%$ & $44 \%$ & & \\
\hline$>\$ 100 \mathrm{~K}$ & $52 \%$ & $47 \%$ & $40 \%$ & $47 \%$ & $46 \%$ & 3.91 & 0.69 \\
\hline Total & & & & & & & \\
\hline
\end{tabular}

\section{References}

1. Thyberg, K.L.; Tonjes, D.J. Drivers of food waste and their implications for sustainable policy development. Resour. Conserv. Recycl. 2016, 106, 110-123. [CrossRef]

2. Von Massow, M.; Parizeau, K.; Gallant, M.; Wickson, M.; Haines, J.; Ma, D.W.L.; Wallace, A.; Carroll, N.; Duncan, A.M. Valuing the Multiple Impacts of Household Food Waste. Front. Nutr. 2019, 6, 143. [CrossRef]

3. Reynolds, C.J.; Mirosa, M.; Clothier, B. New Zealand's Food Waste: Estimating the Tonnes, Value, Calories and Resources Wasted. Agric. 2016, 6, 9. [CrossRef]

4. Willett, W.; Rockström, J.; Loken, B.; Springmann, M.; Lang, T.; Vermeulen, S.; Garnett, T.; Tilman, D.; Declerck, F.; Wood, A.; et al. Food in the Anthropocene: the EAT-Lancet Commission on healthy diets from sustainable food systems. Lancet 2019, 393, 447-492. [CrossRef]

5. Jagau, H.L.; Vyrastekova, J. Behavioral approach to food waste: an experiment. Br. Food J. 2017, 119, 882-894. [CrossRef]

6. Byker, C.J.; Farris, A.R.; Marcenelle, M.; Davis, G.C.; Serrano, E.L. Food Waste in a School Nutrition Program After Implementation of New Lunch Program Guidelines. J. Nutr. Educ. Behav. 2014, 46, 406-411. [CrossRef] [PubMed]

7. Lazell, J. Consumer food waste behaviour in universities: Sharing as a means of prevention. J. Consum. Behav. 2016, 15, 430-439. [CrossRef]

8. Devaney, L.; Davies, A.R. Disrupting household food consumption through experimental HomeLabs: outcomes, connections, contexts. J. Consum. Cul. 2017, 17, 823-844. [CrossRef]

9. Schmidt, K. Explaining and promoting household food waste-prevention by an environmental psychological based intervention study. Resour. Conserv. Recycl. 2016, 111, 53-66. [CrossRef]

10. Priefer, C.; Jörissen, J.; Bräutigam, K.-R. Food waste prevention in Europe-A cause-driven approach to identify the most relevant leverage points for action. Resour. Conserv. Recycl. 2016, 109, 155-165. [CrossRef] 
11. ReFED. A Roadmap to Reduce U.S. Food Waste by 20 Percent. Retrieved October 6th 2019. 2016. Available online: https://www.refed.com/downloads/ReFED_Report_2016.pdf (accessed on 12 December 2019).

12. Gunders, D.; Wedel, C. Save the Food. 2016. Available online: https://www.epa.gov/sites/production/files/ 2016--05/documents/gunders_and_wedel_april_2016.pdf (accessed on 6 October 2019).

13. EPA. Food: Too Good To Waste-An Evaluation Report for the Consumption Workgroup of the West Coast Climate and Materials Management Forum. 2016. Available online: https://www.epa.gov/ sustainable-management-food/evaluation-report-campaigns-using-food-toogood-waste-toolkit (accessed on 12 December 2019).

14. National Zero Waste Council. National Food Waste Reduction Strategy. 2017. Available online: http://www. nzwc.ca/focus/food/national-food-wastestrategy/Documents/NFWRS-Strategy.pdf (accessed on 12 December 2019).

15. Amis de la Terre de Québec. Mobiliser la population québécoise pour réduire le gaspillage alimentaire: un enjeu de développement durable. 2016. Available online: http://www.sauvetabouffe.org/wp-content/ uploads/2016/09/Mémoire-final-mars-2016.pdf (accessed on 12 December 2019).

16. Abrahamse, W.; Steg, L.; Vlek, C.; Rothengatter, T. A review of intervention studies aimed at household energy conservation. J. Environ. Psychol. 2005, 25, 273-291. [CrossRef]

17. Parizeau, K.; Von Massow, M.; Martin, R. Household-level dynamics of food waste production and related beliefs, attitudes, and behaviours in Guelph, Ontario. Waste Manag. 2015, 35, 207-217. [CrossRef] [PubMed]

18. Steg, L.; Vlek, C. Encouraging pro-environmental behaviour: An integrative review and research agenda. J. Environ. Psychol. 2009, 29, 309-317. [CrossRef]

19. Reynolds, C.; Goucher, L.; Quested, T.; Bromley, S.; Gillick, S.; Wells, V.K.; Evans, D.; Koh, L.; Kanyama, A.C.; Katzeff, C.; et al. Review: Consumption-stage food waste reduction interventions-What works and how to design better interventions. Food Policy 2019, 83, 7-27. [CrossRef]

20. Aschemann-Witzel, J.; De Hooge, I.; Amani, P.; Bech-Larsen, T.; Oostindjer, M. Consumer-Related Food Waste: Causes and Potential for Action. Sustainability 2015, 7, 6457-6477. [CrossRef]

21. Davies, J.; Foxall, G.; Pallister, J. Beyond the intention-behaviour mythology: an integrated model of recycling. Mark. Theor. 2002, 2, 29-113. [CrossRef]

22. Stöckli, S.; Niklaus, E.; Dorn, M. Call for testing interventions to prevent consumer food waste. Resour. Conserv. Recycl. 2018, 136, 445-462. [CrossRef]

23. Barr, S. Environmental action in the home: investigating the 'value-action' gap. Geography 2016, 91, 43-54.

24. Visschers, V.H.; Wickli, N.; Siegrist, M. Sorting out food waste behaviour: A survey on the motivators and barriers of self-reported amounts of food waste in households. J. Environ. Psychol. 2016, 45, 66-78. [CrossRef]

25. Young, W.; Russell, S.V.; Robinson, C.A.; Barkemeyer, R. Can social media be a tool for reducing consumers' food waste? A behaviour change experiment by a UK retailer. Resour. Conserv. Recycl. 2017, 117, 195-203. [CrossRef]

26. Shaw, P.J.; Smith, M.M.; Williams, I.D. On the Prevention of Avoidable Food Waste from Domestic Households. Recycling 2018, 3, 24. [CrossRef]

27. Van Der Werf, P.; Seabrook, J.A.; Gilliland, J.A. "Reduce Food Waste, Save Money": Testing a Novel Intervention to Reduce Household Food Waste. Environ. Behav. 2019. [CrossRef]

28. Elimelech, E.; Ayalon, O.; Ert, E. What gets measured gets managed: A new method of measuring household food waste. Waste Manag. 2018, 76, 68-81. [CrossRef]

29. Quested, T.E.; Parry, A.D.; Easteal, S.; Swannell, R. Food and drink waste from households in the UK. Nutr. Bull. 2011, 36, 460-467. [CrossRef]

30. Yamakawa, H.; Williams, I.; Shaw, P.; Watanabe, K. Food waste prevention: lessons from the Love Food Hate Waste campaign in the UK. In Proceedings of the 16th International Waste Management and Landfill Symposium, S. Margherita di Pula, Sardinia, Italy, October 2017; pp. 2-6.

31. Bandyopadhyay, J.; Dalvi, G. Can interactive installations bring about behaviour change? Using interactive installation to change food waste behaviours. In International Conference on Research into Design; Springer: Berlin, Germany, 2017.

32. Lim, V.; Funk, M.; Marcenaro, L.; Regazzoni, C.; Rauterberg, M. Designing for action: An evaluation of Social Recipes in reducing food waste. Int. J. Hum.-Comput. Stud. 2017, 100, 18-32. [CrossRef] 
33. Comber, R.; Thieme, A. Designing beyond habit: opening space for improved recycling and food waste behaviors through processes of persuasion, social influence and aversive affect. Pers. Ubiquitous Comput. 2013, 17, 1197-1210. [CrossRef]

34. Ganglbauer, E.; Fitzpatrick, G.; Comber, R. Negotiating food waste: using a practice lens to inform design. ACM Trans. Comput. Interact. 2013, 20, 1-25. [CrossRef]

35. Tobon, S.; Ruiz-Alba, J.L.; García-Madariaga, J. Gamification and online consumer decisions: Is the game over? Decis. Support Syst. 2019. [CrossRef]

36. Johnson, D.; Deterding, S.; Kuhn, K.-A.; Staneva, A.; Stoyanov, S.; Hides, L. Gamification for health and wellbeing: A systematic review of the literature. Internet Interv. 2016, 6, 89-106. [CrossRef]

37. Hamari, J.; Koivisto, J.; Sarsa, H. Does Gamification Work? A Literature Review of Empirical Studies on Gamification; IEEE: Piscataway, NJ, USA, 2014.

38. Johnson, D.; Horton, E.; Mulcahy, R.; Foth, M. Gamification and serious games within the domain of domestic energy consumption: A systematic review. Renew. Sustain. Energy Rev. 2017, 73, 249-264. [CrossRef]

39. WRAP (Waste and Resources Action Programme). Household Food and Drink Waste in the UK. WRAP, UK. 2009. Available online: https://www.wrap.org.uk/sites/files/wrap/Household_food_and_drink_waste_in_ the_UK___report.pdf (accessed on 19 January 2020).

40. FLWP (Food Loss and Waste Protocol). Food Loss and Waste Accounting and Reporting Standard (Version 1.0). Washington DC: World Resources Institute. 2016. Available online: https://www.wbcsd.org/Programs/Food-and-Nature/Food-Land-Use/Climate-Smart-Agriculture/ Resources/Food-Loss-and-Waste-Accounting-and-Reporting-Standard (accessed on 19 January 2020).

41. Newey, W. Course Materials for 14.386 New Econometric Methods, MIT Open CourseWare. Massachusetts Institute of Technology. Retrieved January 18th 2020. 2007. Available online: https://ocw.mit.edu/ courses/economics/14--386-new-econometric-methods-spring-2007/readings/treatment_effect.pdf (accessed on 19 January 2020).

42. Hebrok, M.; Boks, C. Household food waste: Drivers and potential intervention points for design-An extensive review. J. Clean. Prod. 2017, 151, 380-392. [CrossRef]

43. Qi, D.; Roe, B.E. Household Food Waste: Multivariate Regression and Principal Components Analyses of Awareness and Attitudes among U.S. Consumers. 2016. Available online: https://journals.plos.org/plosone/ article?id=10.1371/journal.pone.0159250 (accessed on 19 January 2020).

44. Van der Werf, P. Single Family Curbside Waste and Participation Audit. 2cg Waste Management Consulting Services. London, Ontario. 2016. Available online: http://thecif.ca/wp-content/uploads/2016/09/873-Toronto_ Final_Report.pdf (accessed on 19 January 2020). 